\title{
An Exploration of Midwives' Experiences of Reducing Maternal Morbidity and Mortality From Postpartum Haemorrhage (PPH) in Rural Communities in Eastern Nigeria.
}

\author{
Felicity Agwu Kalu ( $\nabla$ f.kalu@qub.ac.uk) \\ Queen's University Belfast \\ Joan Nkechi Chukwurah \\ University of Benin
}

\section{Research Article}

Keywords: Postpartum haemorrhage, Prevention and Management of PPH, Active management of the third stage of labour, Antenatal anaemia, Reducing maternal morbidity and mortality, Midwives, Competent and compassionate care, Collaboration with multidisciplinary team, Cultural competency, Access to maternity care services.

Posted Date: October 22nd, 2021

DOI: https://doi.org/10.21203/rs.3.rs-954172/v1

License: (c) (i) This work is licensed under a Creative Commons Attribution 4.0 International License. Read Full License 


\section{Abstract \\ Background}

Postpartum haemorrhage (PPH) is one of the major complications of childbirth which results in maternal morbidity and mortality especially in low and middle-income countries like Nigeria. Midwives play a vital role in preventing and managing PPH in Nigerian rural communities. The aim of this study is to understand the experiences of midwives in rural maternity care settings in order to provide appropriate support and improve practice.

\section{Methods}

An exploratory qualitative study of a purposive sample of 15 practicing midwives was carried out using semi-structured interviews from November 2018 to February 2019. Data were transcribed verbatim and analyzed using content analysis.

\section{Results}

Four themes were identified; intervention for preventing PPH, approaches to managing $\mathrm{PPH}$, challenges of preventing and managing $\mathrm{PPH}$, and ways of supporting midwives to overcome the challenges of preventing and managing PPH in rural health care settings. Midwives employed various strategies, such as antenatal education, diagnosis, and treatment of anaemia to prevent PPH. Their understanding of the condition as a life-threatening condition enabled the midwives to provide holistic and effective management that sometimes involved multidisciplinary team approach. However, inadequate resources and delay in seeking health care services militate against their efforts. The midwives also identified the need for continuing education and training as means of enhancing their standard of care.

\section{Conclusion}

These midwives in Nigerian rural health care setting engage in preventive practices and active management of PPH though not without barriers, such as inadequate resources. There is need for the midwives in rural areas to have cultural competence, be provided with adequate resources and participate in ongoing education to be more effective.

\section{Background}

Pregnancy and childbirth are times of joy and celebrations for many families however these periods are also challenging moments for some families because of frightening and traumatic experiences of maternal morbidity or mortality associated with postpartum haemorrhage (PPH) or other complications of pregnancy and childbirth (1-4). Globally, 830 women die daily because of preventable complications 
of pregnancy and childbirth (1). According to the World Health Organisation (WHO), 99\% of the deaths occurred in several low and middle-income countries, with an estimation of 814 maternal mortality per 100,000 live births reported in Nigeria $(1,24)$.

The recent National Demographic Health Survey showed a slight reduction of Maternal Mortality Rate (MMR) from 814 to 556 per 100,000 live births (5). Although this reduction of maternal mortality rate is a welcomed sign of slight improvement, the overall high rate of maternal death in Nigeria is quite disturbing and far from reaching the 2016-2030 Sustainable Development Goals target of improving maternal health and wellbeing and reducing maternal death to less than 70 per 100, 000 live births $(1,6)$. The high maternal mortality rate therefore presents a major maternal healthcare challenge nationally and internationally in relation to identifying the causes of death and taking appropriate actions to continuously improve women's health and save their lives (3-4).

Evidence from the literature has shown that PPH is a major cause of death in low and middle-income countries such as Nigeria $(3,7-12)$. This occurs when there a genital blood loss of $500 \mathrm{mls}$ or more in the first 24 hours following childbirth $(7,10,13)$. Minor PPH is described as blood loss of $500-1000 \mathrm{mls}$ while major PPH is blood loss of above $1000 \mathrm{mls}$ (13). The effects of the blood loss on women vary and highlights the importance of timely individualised women-centred care $(9,13,14)$. Hypovolaemic shock, multiorgan failure, and maternal death can occur depending on the severity of PPH, pre-existing anaemia, untreated or ineffective treatment and management of $\mathrm{PPH}(2,14,15)$. Prevention of anaemia in pregnancy, appropriate management of first and second stages of labour, effective physiological (without medication) or active management (with medications) of third stage of labour are some of ways through which PPH can be prevented $(2,9,12,16-21)$. The literature has shown that prompt diagnosis and treatment is essential for effective management of PPH and minimising the incidence of morbidity and mortality associated with $\mathrm{PPH}(2,10,12,19)$. Studies have shown that high rate of maternal mortality and morbidity in Nigeria is associated with factors such as delay of women in seeking maternity care, delay in arriving at the health care facilities, and delay in receiving care from skilled healthcare professionals (22-24). Although several studies have been conducted to investigate the causes and treatment of PPH in Nigeria \& worldwide $(3,8,14,25-26)$, published evidence of the experiences of midwives involved in preventing and managing PPH in rural settings of Nigeria is lacking. Given the fact that midwives are mostly the skilled professional maternity care providers in the rural communities, the understanding of their experiences in these maternity care situations is essential for providing adequate support to them to enhance their abilities to providing appropriate care to women in an ongoing manner, hence the need for this study.

\section{Methods}

\section{Study Design}

This qualitative study was carried out to explore midwives' experiences of reducing maternal mortality and morbidity from PPH in a rural community in rural Eastern Nigeria. 


\section{Participants and recruitment}

A purposive sample of 15 qualified and practicing midwives who had experiences of preventing and managing PPH willingly participated in the study. An administrative staff in the labour ward acted as a gatekeeper in recruitment of the participants. The process of recruitment involved issuing an initial notice about the study and invitation to participate. Information leaflet was issued subsequently.

\section{Ethical consideration}

Ethical approval of the study was obtained from the research ethics committee of three health facilities in South-eastern Nigeria, and Trinity College Dublin, Ireland. The first author (FAK) obtained written informed consent from each participant before each interview. Each of the participants was given adequate time (one week) to read the participant information sheet and ask any question that requires clarification before signing the consent form. To enhance anonymity, pseudonyms were used for the participants and all identifying information about them were removed before analysing the data.

\section{Data collection}

Data were collected by the first author (FAK) through semi-structured interviews with 15 willing participants from November 2018 to February 2019. The interviews took place at convenient locations identified by the participants. An interview guide with introductory open-ended such as: Please tell me about your experiences of preventing and managing PPH. What is it like to prevent PPH in a rural community in Nigeria? What is it like to treat and manage PPH in a rural community in Nigeria? The interview guide can be seen in the supplementary file. The rationale for using semi-structured interviewing was to enable the participants to freely respond in their own words and explain their experiences of the phenomena. The use of semi-structured interviews also provided additional benefits of enabling the researchers to probe and clarify some points with the participants in a more flexible way. The interviews lasted between 40 and 55 minutes. Interviews were audio-recorded. The use of purposive sample in this study helped in obtaining rich information and in-depth understanding of experiences of reducing maternal mortality and morbidity from PPH in a rural community in rural health care settings. Data were transcribed verbatim. Data saturation occurred after 15 interviews. This means that no new theme emerged from the data. Data saturation was confirmed by both authors (FAK and JNC).

\section{Data analysis}

Data were analysed independently by the first (FAK) and second (JNC) authors using qualitative content data analysis to provide new insights and more understanding of the experiences of midwives in preventing and managing PPH and to inform practical action (27-29). Specifically, a content analysis approach identified by Graneheim and Lundman (27) was used to guide the data analysis towards understanding the experiences of the midwives. The transcripts were read and re-read by each author and those words and sentences containing evidence and information regarding the research question were classified as meaning units. This was followed by condensing and coding of the meaning units, which 
were further sorted into their corresponding categories. Finally, the underlying meaning of the categories were organized into their respective themes. The findings of both authors were discussed together to get consensus. Four themes that reflected the aim of the study emerged from data analysis and were approved by both authors.

\section{Data trustworthiness}

Data trustworthiness was achieved using Lincoln \& Guba's framework for ensuring rigor as a guide. This framework includes credibility, transferability, dependability, and confirmability (30). To achieve credibility of the study, participants were used for member checking to confirm accuracy of the themes. During the interviews, participants were encouraged to clearly explain the meaning of their experiences. Credibility of the study was further enhanced through reflexivity $(31,32)$. In relation to transferability of the study findings, the researchers have placed the study in context by providing readers with examples of other studies with similar phenomena in the discussion section. Dependability is about the extent of the stability of the findings over time (30). The phenomena of interest in this study, the design and methods remained the same throughout the study to enhance dependability. In this study, confirmability was achieved by ensuring the credibility, transferability, and dependability of the study.

\section{Reflexivity}

The researchers kept reflective research diaries and remained engaged in critical self-awareness throughout the research process to prevent bias. In addition, the research knowledge and skills of the researchers, and their knowledge and previous experiences of preventing and managing PPH as midwives enabled them to be theoretically sensitive to the data that were emerging. Furthermore, their professional background as midwives, helped the interviewer (FAK) to communicate effectively with participants who were midwives, as the researchers shared similar background knowledge and vocabulary with them.

\section{Results}

A total of 15 midwives participated in the study. All the participants were registered midwives and nurses. Table 1 provides other details of demographic characteristics of the study participants. Data analysis revealed four themes: (a) Interventions for preventing PPH; (b) Approaches to managing PPH (c) Challenges of preventing and managing PPH; (d) Ways of supporting midwives to overcome the challenges of preventing and managing PPH in rural health care settings. Table 2 demonstrates how the themes were developed from sub-categories to categories and then themes. 
Table 1

Demographic characteristics of the study participants

\begin{tabular}{|lll|}
\hline Characteristics of the participants & N & $\%$ \\
\hline Female & 15 & $100 \%$ \\
\hline Agle & 0 & $0 \%$ \\
$30-39$ & 2 & $13.3 \%$ \\
$40-49$ & 5 & $33.3 \%$ \\
$50-59$ & 8 & $53.3 \%$ \\
\hline Level of Midwifery Education & 12 & $80.0 \%$ \\
Certificate & 3 & $20.0 \%$ \\
BSc. & & \\
\hline Length of Midwifery practice & 2 & 13.3 \\
3-4 years & 2 & 13.3 \\
5-6 years & 11 & 73.3 \\
Over 10 years & & \\
\hline Current area of practice & 2 & 13.3 \\
Labour and Birth & 13 & 86.7 \\
Labour, Birth \& Postnatal care & & \\
\hline
\end{tabular}


Table 2

Themes, categories, and sub-categories from midwives' experiences of reducing maternal morbidity and mortality from postpartum haemorrhage

\begin{tabular}{|c|c|c|c|}
\hline & Themes & Categories & Sub-Categories \\
\hline \multirow[t]{3}{*}{1} & \multirow[t]{3}{*}{ Interventions for preventing $\mathrm{PPH}$} & $\begin{array}{l}\text { Antenatal care } \\
\text { interventions }\end{array}$ & \multirow{3}{*}{$\begin{array}{l}\text { Antenatal } \\
\text { assessment, } \\
\text { diagnosis, and } \\
\text { treatment of anaemia } \\
\text { Antenatal education } \\
\text { and health promotion }\end{array}$} \\
\hline & & \multirow{2}{*}{$\begin{array}{l}\text { Interventions for } \\
\text { preventing PPH } \\
\text { during labour and } \\
\text { childbirth }\end{array}$} & \\
\hline & & & \\
\hline \multirow[t]{2}{*}{2.} & \multirow[t]{2}{*}{ Approaches to PPH management } & Physical care & \\
\hline & & Emotional care & \\
\hline \multirow[t]{3}{*}{3} & \multirow[t]{3}{*}{$\begin{array}{l}\text { Challenges associated with prevention and } \\
\text { management of PPH }\end{array}$} & $\begin{array}{l}\text { Issues with access to } \\
\text { maternity care } \\
\text { services }\end{array}$ & \\
\hline & & $\begin{array}{l}\text { The effects of } \\
\text { inadequate resources }\end{array}$ & \\
\hline & & $\begin{array}{l}\text { on prevention and } \\
\text { management of } \mathrm{PPH}\end{array}$ & \\
\hline 4 & $\begin{array}{l}\text { Ways of supporting midwives to overcome } \\
\text { the challenges of preventing and managing } \\
\text { PPH in rural health care settings }\end{array}$ & & \\
\hline
\end{tabular}

\section{Theme 1: Interventions For Preventing Pph}

This theme deals with the strategies used by the midwives to prevent PPH and reduce potential complications associated with PPH. This theme contains two categories namely: (a) Antenatal care interventions (b) Interventions during labour and birth

\section{Antenatal care interventions for preventing PPH}

Antenatal care provided opportunities for assessing and promoting maternal well-being in general, and preventing PPH through assessment, diagnosis, and treatment of risk factors associated with the development of anaemia during pregnancy. This category contains two sub-categories: (a) antenatal assessment, diagnosis, and treatment of anaemia; (b) antenatal education and health promotion.

\section{Antenatal assessment, diagnosis, and treatment of anaemia}

Antenatal assessment and screening were among the strategies used to prevent PPH. Women were encouraged to book early to enhance early investigations and identifications of risk factors for PPH such 
as anaemia. Full blood counts were routinely tested to assess and monitor the levels of women's haemoglobin as well as correcting anaemia in pregnancy.

"The rate of anaemia in Nigeria is alarming and killing many people. We do routine laboratory investigations of clients' HB during pregnancy. Many women have low HB and low PCV because of poor diet. Women with low HB and low PCV levels are treated for anaemia with iron therapy during pregnancy".

"I monitor the haemoglobin level of all pregnant women. This helps to prevent and correct anaemia before labour and delivery of the baby"

"Antenatally, I encourage pregnant women to book on time at gestational age of 12-16 weeks. I check the level of the women's PCV, that is, packed cell volume. We give them advise according to the results".

The midwives also discussed how pregnant women were prophylactically treated for malaria to reduce malaria related anaemia.

"We give preventive treatment to prevent malaria during pregnancy because malaria can lead to anaemia during pregnancy".

The midwives emphasized that since PPH is not always predictable, efforts should be made to maintain optimum haemoglobin levels during the antenatal period to enhance women's abilities to cope with PPH if it occurs.

"It is not always easy to predict who will have PPH based on risk factors because few of the women who had PPH had no risk factor. It is better to make efforts during pregnancy to improve women's HB level before labour so that her blood loss during childbirth will not have bad effect on their health".

\section{Antenatal education and health promotion.}

Antenatal education provided opportunities for health education aimed at promoting women's health and wellbeing during pregnancy. The importance of eating healthy diet was discussed during antenatal education. The benefits of birthing in the health facilities were also discussed.

"PPH is prevented by educating the mother from antenatal clinic during first, second and third trimesters on how to promote and maintain good health during pregnancy.

Health education is also provided to the women on the importance of hospital delivery"

"Antenatal health education is a very good tool. I advise women to eat balanced diet to prevent anaemia."

Some midwives were unable to provide adequate antenatal health education to some women because of poor maternal health literacy, language barrier, personal, religious, and spiritual beliefs held by the women. 
'The hindrances we do have for effective prevention of PPH in the community clinic are some patients' attitudes to accepting antenatal talk on healthy diet in pregnancy due to their religious beliefs and status which may result in poor feeding and anaemia. Some women are also reluctant to accept family planning talk antenatally. They don't know the dangers of uterine atony due to multiparity".

"Illiteracy of some of the women can be challenging. Some women believe that PPH is caused by an enemy or witchcraft. It is difficult to explain to such people the actual cause of PPH when they have a very strong belief that it was caused spiritually by an enemy"

"Illiteracy among some of the rural women is a hindrance to successful antenatal education and health promotion because some of them lack understanding of complications of PPH. Language barrier makes it hard for us to fully explain complications of PPH and what to do to prevent PPH antenatally"

\section{Intervention for preventing PPH during labour and childbirth}

Midwives employed a variety of measures when managing all stages of labour to minimise the risks of $\mathrm{PPH}$. They also identified the importance of managing physical labour pain as well as providing emotional support to the woman. Pharmacological and non-pharmacological pain management options were used to promote women's comfort. Efforts were made to minimize the risks of bleeding from perineal trauma by guarding the perineum during childbirth, minimising the use of episiotomy and timely suturing of the perineum. The clinical skills and experiences of the midwives contributed to effective management of the various stages of labour.

"How I manage 2nd and 3rd stages of labour in labour ward are important. Labour pain is not an easy one, so I always encourage the women not to bear down before time. I relief them from pain a bit with sacral massage, telling the woman stories, reassure her and intramuscular analgesia. I always guard the perineum during delivery to prevent tear and bleeding".

"I eliminate or at least minimise the use of episiotomy "I suture any tear sustained or episiotomy given soon after the baby is born. This helps to reduce bleeding from any perineal tear that requires suturing. All stages of labour can be well managed with experience and these actions help to prevent PPH".

The third stage of labour was actively managed by all participants. The importance of accurate assessment of risk factors associated with PPH, accurate estimation of blood loss and careful monitoring of the woman's condition and side effects of medication were discussed.

"In order to prevent this deadly condition (PPH), I try to accurately assess the risk factors and blood loss. Our health care facility guidelines encourage the practice of active management of third stage of labour. This have helped to reduce the number of PPH cases in our health care facility. I administer a uterotonic drug immediately after the birth of the baby. I also use controlled cord traction when delivering the placenta. We use oxytocin as our first choice of drug but we try to be careful of oxytocin induced hypotension and tachycardia by monitoring vital signs. 
"What helps me to prevent PPH is the use of misoprostol, good history taking and careful conducting of delivery"

\section{Theme 2: Approaches To Pph Management}

The midwives' understanding of PPH as an emergency, frightening and life-threatening condition enhanced their abilities to provide prompt physical and emotional care to the women and their birth partners to reduce the risks of physical complications and emotion distress. The midwives also discussed the challenges they experienced when managing PPH. Thus, the theme contains three categories namely: (a) Physical care following PPH, (b) Emotional support; (c) Challenges in managing $\mathrm{PPH}$.

\section{Physical care}

The midwives identified PPH as an obstetric emergency that required prompt recognition, diagnosis, treatment to control the bleeding and prevent deterioration. The participants explained that having guidelines and policy for preventing and managing PPH in their wards/units enabled them to diagnose, treat and manage PPH in a timely and effective manner.

"We used and followed the algorithm for management of PPH. This helped us to diagnose and treat PPH without wasting time. PPH was mainly caused by atonic uterus.

Sometimes the steps in diagnosing and managing PPH happen at the same time. Having another midwife or doctor in the room to help was very useful".

"Our guidelines start with history taking. Noting any history of previous PPH help me to prepare properly to prevent and manage PPH as required. My emergency and midwifery care involves prompt diagnosis and treatment of the problem to minimise serious sequela like shock, anaemia, and prolonged stay in the health care facility".

"PPH can be deadly, so we treat it as an emergency and try to implement the health facility protocol in a manner similar to cardiac arrest protocol, with the same attention to detail and documentation"

The midwives' abilities to diagnose and treat PPH effectively were also influenced by their levels of knowledge, skills, clinical experiences, and availability resources including staff.

"As a midwife, I have a lot of knowledge, clinical experience, and skills for managing PPH. "It is an emergency, both material and medical manpower must be on hand, decisions and actions must be taken adequately to save the life of the patient and prevent complications".

"I was adequately prepared to manage $\mathrm{PPH}$. I received adequate education and training on PPH management during my midwifery education program. I am a registered nurse and midwife. I have had a 
lot of opportunities to work with more qualified midwives and learnt from them. The knowledge and experiences I gained have helped me to effectively manage PPH as a qualified nurse and registered midwife.

\section{Emotional care}

The midwives spoke about PPH as a frightening condition requiring physical, emotional, and spiritual considerations and care. The importance of providing care in a competent, compassionate, and sensitive manner to reduce anxiety and psychological distress for the women was emphasized.

"Managing PPH needs everything possible to tackle the problem. It is between life and death and so we did everything to tackle it competently with knowledge and skills, and with all sensitivity to reduce the fear of the patient and save her life"

"PPH is an emergency, I try to be tactful and confident when the woman is bleeding heavily because the patient is always anxious and afraid of what might happen to her. I render care and reassurance in sensitive and skilful ways.

The midwives discussed the importance of actively communicating with the woman and her partner to enhance their active participation in their care and alleviate their anxiety. The midwives demonstrated their abilities to pay attention to them and show empathy in the given situations.

"PPH is not just about physical care. It a life-threatening and traumatic experience for women especially when bleeding is severe. I feel for the woman and her birth partner. I try to pay attention to their needs and communicate with them with compassion and sensitivity".

"I always involve the woman in her care. I talk with her and draw her attention to what is happening before starting any intervention. I explain everything to her and make sure she understands what is happening and what we want to do to make her feel better".

Religious and spiritual beliefs are sources of inner strength for many individuals. Severe PPH disrupts the spiritual conditions of some of the midwives and the women.

'PPH is an obstetric emergency and time is everything, but by God's interventions and careful detection of the cause of the bleeding, we were able to control the bleeding

"To manage PPH is not an easy task especially if the PPH is severe. It disorganises spiritual and physical conditions of the midwife and the patient".

With God's help and team effort we were able to control the bleeding

\section{Theme 3: Challenges associated with prevention and management of PPH}

The prevention and management of PPH posed considerable challenges to the midwives in rural clinical setting and communities. Hindrances to the provision of effective care in relation to PPH prevention and 
management included issues with access to maternity care services, and inadequate resources for managing PPH. Ways of overcoming challenges of preventing and managing PPH in rural health care settings were also discussed.

\section{Issues with access to maternity care services}

Problems with access to the maternity care centres resulted in delay in treatment of women who had $\mathrm{PPH}$. These include difficulties with transportation, and late referral from maternity home to health care facilities.

"We have so many challenges. For example, some roads are not good, there is poor accessibility to health facility. There is poverty amongst Nigerian many women. Some of them live far away from the health facility and have no car. Public transportation system is not reliable. These problems lead to delays in getting to the health care facility and delay in treatment especially if the baby was born before arrival to the health facility"

"Late referral from maternity home is not helpful. It leads to delay in treating the woman. The day we had PPH case in our facility, actually it was referred from a nearby maternity home".

\section{The effects of inadequate resources on prevention and management of PPH}

Inadequate resources were identified as a major barrier to the midwives' efforts in adequate prevention and management of PPH in the rural communities. Insufficient resources such as infrastructure, labour ward equipment, laboratory facilities, medication, staff shortages were inhibitory factors for the provision of timely and adequate care to women in the rural communities.

"What inhibit my ability to effective prevention and management of PPH in health facility is that we don't have adequate equipment and drugs. We don't have lab for grouping and cross matching. We don't have enough staff in the facility. Imagine in the health facility you see only one midwife doing everything alone, and you just have a maternity care attendant to help you"

"There is a lack of some equipment in the clinic, for example, equipped labour ward with theatre, in case of emergency caesarean section, and instruments for instrumental deliveries. We have few delivery kits".

"It was not easy managing PPH in the local area where there is no adequate equipment, drugs and staff. Many midwives and other health care workers don't want to go to rural areas to work because there is no road, no electricity, no properly equipped health care facility".

Although the effective management of PPH were challenging, the midwives were motivated by the passion they had for their work, and determination to save women's lives. These resulted in their job satisfaction. 
"Actually, it has not been easy managing PPH, but one feels satisfied when you have achieved your aim of controlling the bleeding and saving the life of the woman".

"Determination is the key to success. I like my job as a midwife. I feel satisfied when I can help my patients and when the bleeding is well managed".

\section{Theme 4: Ways of supporting midwives to overcome the challenges of preventing and managing PPH in rural health care settings}

It is essential that midwives are adequately supported by their organisations and the government to overcome the challenges of inadequate resources including human resources to enhance their abilities to prevent and manage PPH effectively in rural health care settings.

"We will prefer to have a well-equipped labour room where we will have facilities that will enable us control bleeding for example, a bed where patient can be placed in a lithotomy position if necessary and placenta is expelled with its membranes completely with an angle light for easy assessment"

"Government should employ more trained midwives. We need more midwives in the labour ward. We also need enough equipment and drugs for managing PPH. More doctors should be assigned to work in the health facilities in the rural areas"

Effective management of PPH in an on-going manner requires continuous practice review, emergency drills and continuing education and training of midwives. These actions are necessary for the provision of high standard of care to women in the rural health care settings.

"Just as with other advanced life support protocols, it is important to have a periodic review of everybody's practice. We also need practice drills. Practice review is helpful in improving practice.

"I have gone to various training such as LSS training, that is, life-saving skills; Mc pop training, that is, mandatory continuing professional development programme;

DEAQHSN - Delivering Effective and Quality Health Service in Nigeria (training); PAHCG (A Pivot to Adequate Health Care at the Grassroot), etc. These trainings occur once every three to four years".

"I need continuous training and retraining because practices are changing as well as drugs used in management of illnesses".

Effective management of massive PPH is dependent upon timely collaborative multidisciplinary team approach. Midwives are therefore encouraged to escalate care in a timely manner to their senior colleagues and other multidisciplinary team members such as the obstetricians and anaesthetists for women experiencing severe PPH to enhance optimum provision of care to them.

"As a midwife, I was involved with the multidisciplinary team including obstetricians and anaesthetists in looking after patients diagnosed to have intractable post-partum haemorrhage and not managed with 
standard medical treatment and were subsequently treated with operative interventions. The operative interventions were successful"

"Midwives should not delay in transferring care to doctors if they can't control the bleeding. More studies are required on how to recognise and rectify any deficiencies in midwifery practice for urgent transfer of patient for surgery if indicated. If bleeding cannot be managed by midwives, they must transfer the care to doctors because surgery may be required to save the woman's life".

\section{Discussion}

The quality of care received by women during pregnancy, labour and childbirth contribute to their overall states of health and wellbeing. This study explored midwives' experiences of reducing maternal morbidity and mortality from post-partum haemorrhage (PPH) in rural communities in Eastern Nigeria. Midwives in this study employed various strategies during antenatal care, labour, and birth to prevent PPH. Antenatal care interventions involving antenatal education, assessment, screening, diagnosis, and treatment of anaemia to ensure optimum haemoglobin level prior to labour and birth of the baby. Studies have shown that the effects of the blood loss on women vary, therefore prevention of anaemia during pregnancy is crucial in minimizing potential risk of morbidity and mortality associated with $\mathrm{PPH}(9,13-14)$. Some women's reluctances to accept antenatal education were attributed to poor maternal health literacy, language barrier, personal and spiritual beliefs held by the women. Evidence has shown that poor maternal education, poor knowledge about anaemia in pregnancy, lack of antenatal education and some cultural beliefs are some of the factors responsible for maternal anaemia in Nigeria (33).

Nigeria is a multicultural, multireligious and multilingual country. To be able to provide holistic womencentred maternity care to all women, it is important that midwives understand and appreciate the roles of culture, religion, and spiritual beliefs in the lives of many individuals in Nigeria (34-35). Being culturally competent will enable midwives to understand, appreciate, and interact with women from different cultural and religious backgrounds (35-36). The use of professional interpreter during antenatal education will also help to alleviate language and communication difficulties experienced by the midwives and the women (37).

Prophylactic malaria treatment was another strategy used to reduce the risks of anaemia during pregnancy. Studies have found that prophylactic treatment for malaria or existing malaria in countries with moderate to high prevalence of malaria helps to inhibit or minimize the risks of the invasion activities of malarial parasites on the red blood cells, thus reducing the risks of maternal anaemia, placental malaria, premature labour, and pregnancy loss $(1,38-39)$. To minimize the risks of poor compliance with malaria treatment, women should be given options of medication with minimal side effects (38).

The midwives' clinical skills and experiences and continuity of care enabled them to use strategies such as guarding the perineum during childbirth, minimising the usage of episiotomy and timely suturing of the perineum to reduce bleeding. These findings demonstrate the importance of acquired skills and 
experiential learning in a practice-based profession such as midwifery (40-41). Active management of third stage of labour including the use of oxytocin drugs was beneficial in minimising the risk of PPH. However, lack of access to oxytocic resulted in the use of misoprostol in one of the health care centres. Although misoprostol is not as effective as oxytocin, it is mostly used as a first line drug of choice in low socioeconomic settings because it is less expensive and can be readily stored (42). This has implication for quality of care and timely control of bleeding. Although oxytocin has great impact on reducing PPH, its quality and impact on PPH decreases because of its sensitivity to heat, and the need of appropriate storage in a cold chain of 2-8 degrees centigrade (43). The usage of uterotonic agents in countries such as Nigeria where there is generally hot weather and high temperature, together with unstable electricity for the storage of the uterotonic agents in refrigerators has implications for effective management of PPH especially in rural communities. This highlights the need for additional research to investigate and find out alternative medications that will be more effective in such settings.

The midwives' understanding and appreciation of PPH as a life-threatening and frightening condition served as an enabling factor for the effective management of PPH that involved a holistic approach to care and collaborative multidisciplinary team approach where possible. Studies have shown that to prevent physical deterioration and psychological distress, it is important to utilise timely holistic approaches involving effective team collaboration when managing life-threatening conditions or other complications associated with childbirth $(19-20,44)$.

The midwives' work commitments, passions for their jobs and determination to save women's lives despite insufficient resources added to their senses of achievement and job satisfaction. It has been suggested that having positive mental attitude enhances growth of passion and work engagements at work, increased job satisfaction and well-being. These in turn promotes individuals' effectiveness at work (45).

Barriers to timely prevention and management of PPH reported by the midwives in the current study were issues relating to inadequate resources including staff shortages, insufficient equipment and medications, and delay of some women in arriving at the maternity care centres. Studies have shown that timely maternal care provision in Nigeria is hindered by women's delay in making decision to seek maternity health care, delay in locating or arriving at the health care facilities, and delay in receiving care from skilled health care professionals on arrival to the maternity care facility $(22-23,20)$. To address these challenges, it is therefore important to improve access to maternity care, skilled health care professionals, as well as providing adequate resources including human resources to enhance equitable access to good quality care to these women (20).

Although the midwives acknowledged having adequate knowledge and skills required to manage $\mathrm{PPH}$, they also identified the need for continuing professional education and training, emergency drills, and continuous practice review to enhance their abilities to provide high standard of care to women in the rural health care settings in a consistent manner. These could be achieved by promoting lifelong learning 
and midwives' continuing professional development using a variety of learning strategies involving theoretical inputs, clinical practice, reflective practice, and quality improvement initiatives (46).

\section{Conclusion}

Post-partum haemorrhage is one of the leading causes of maternal death in Nigeria and globally. Exploring the experiences of maternity health care professionals such as midwives is important in identifying ways of improving maternal health and reducing death associated with $\mathrm{PPH}$. Antenatal education, assessment maternal health and wellbeing, diagnosis, and treatment of anaemia were strategies used to prevent anaemia during the antenatal period.

The midwives' knowledge, clinical skills and experiences, and active management of labour were enabling factors for preventing PPH during labour, and childbirth. The midwives' understanding of PPH as an emergency, frightening and life-threatening condition facilitated their prompt provision of the required physical and emotional care to the women and their birth partners. Timely multidisciplinary team approach is essential for effective management of severe PPH. Barriers to timely prevention and timely management of PPH include issues relating to staff shortages, insufficient equipment and medications, and delay of some women arriving at the maternity care centres.

Given that poor maternal health literacy, language barrier, personal and spiritual beliefs held by some of the women hindered effective antenatal education at times, it is important that midwives are culturally competent when providing care to women from different cultural and religious backgrounds. It is also recommended that suitable professional interpreters be provided to enhance communication between midwives and the women. There is a need for organisations and government to provide adequate resources required for preventing and managing $\mathrm{PPH}$ in the rural health care settings to reduce the risks associated with maternal morbidity and mortality in these health care settings.

\section{Abbreviations}

$\mathrm{PPH}$

Postpartum haemorrhage

WHO

World Health Organisation

MMR

Maternal Mortality Rate

\section{Declarations}

\section{Ethics approval and consent to participate}

Ethical approval of the study was obtained from the research ethics committee of the three health facilities in South-eastern Nigeria, and Trinity College Dublin, Ireland. The first author (FAK) obtained 
written informed consent from each participant before each interview. Each of the participants was given adequate time (one week) to read the participant information sheet and ask any question that requires clarification before signing the consent form. To enhance anonymity, pseudonyms were used for the participants and all identifying information about them were removed before analysing the data. Research work was performed in accordance with the Helsinki Declaration of 1964 and its later amendments.

\section{Consent for publication}

Not Applicable

\section{Availability of data and materials}

The dataset used and analysed during the current study are available from the corresponding author, f.kalu@qub.ac.uk on reasonably request.

\section{Competing interests}

The authors declare that they have no competing interests.

\section{Funding}

This study was self-funded.

\section{Authors' contributions}

FAK contributed to the study conception and design, collected data, contributed to analysis and interpretation of data, and drafted the manuscript. JNC contributed to the study conception and design, analysis and interpretation of data, and writing of the manuscript. All authors read and approved the final manuscript.

\section{Acknowledgements}

Not Applicable

\section{Authors' Information}

\section{Affiliations}

!School of Nursing and Midwifery, Queen's University Belfast, Northern Ireland. ${ }^{2}$ Department of Nursing Science, University of Benin, Nigeria.

\section{References}


1. World Health Organisation. Trends in maternal mortality: 1990 to 2015 Estimates by WHO, UNICEF, UNFPA, World Bank Group and the United Nations Population Division. World Health Organisation, Geneva.

2. Niflot LT, Sandven I, Stray-Pederson B, Pettersen S, Al-Zirgq I, Rosenberg M., Jaconsen AF, Vangen S. Risk factors for severe postpartum hemorrhage: a case-control study. BMC Pregnancy and Childbirth. 2017; 17:17.

3. Okonofua F, Imosemi D, Igboin B, Adeyemi A, Chibuko C, Idowu A, Imongan W. Maternal death review and outcomes: An assessment in Lagos State, Nigeria. PLOS ONE. 2017; http://doi.org/10.1371/journal.pone.0188392. Accessed 11 October 2018.

4. Kanchan MI, Chattopadhyay A, Anand A, Naskar TK, Chakraborty S. Analyzing the etiology behind maternal mortality associated with antepartum, intrapartum, and postpartum cases in a tertiary care teaching hospital of West Bengal. Journal of the Turkish-German Gynecological Association. 2018; doi: 10.4274/jtgga.2017.0136.

5. National Population Commission. Nigeria Demographic Health Survey. 2019; https://dhsprogram.com>pubs>pdf. Accessed 12 March 2021.

6. Alkema L, Chou D, Hogan D, Zhang S, Moller AB, Gemmill A, Fat DM, Boerma T, Temmerman M, Mathers C, Say L. Global, regional, and national levels, and trends in maternal mortality between 1990 and 2015, with scenario-based projections to 2030: a systematic analysis by the UN Maternal Mortality Estimation Inter-Agency Group. 2015; http://dx.doi.org/10.10.1016/S0140-6736(15)008387. Accessed 26 April 2021.

7. Lubaki J.P.F, Ngolo J.R.M., \& Maniati L. Z. (2010) Active management of third stage of labour, postpartum haemorrhage and maternal death rate in the Vanga Health Zone, Province of Bandundu, Democratic Republic of Congo. African Journal of Primary Health Care \& Family Medicine 2(1), http://www.phcfm.org

8. Pembe A. B., Paulo C., D’Mello B. S., \& Roosmalen J. V. (2014) Maternal mortality at Mulimbi national hospital in Dar-es-salaam, Tanzania in the year 2011. BMC Pregnancy \& Childbirth 14:320, http://www.biomedicalcentral.com/1471-2393/14/320.

9. Onyema OA, Cornelius AC, Ejelonu ET, Duke OA, Primary postpartum haemorrhage in Federal Medical Centre, Owerri, Nigeria: A six-year review. Nigeria Journal of Medicine. 2015; 24(3):242-5.

10. Kebede BA, Abdo RA, Anshebo AA, Gebremariam BM, Prevalence and predictors of primary postpartum hemorrhage: An implication for designing effective intervention at selected hospitals, Southern Ethiopia. PLOS ONE. 2019; 14(10):e0224579. https//:doi.org/10.1371/journal.pone.0224579.

11. Fawcus $S$. Practical approaches to managing postpartum haemorrhage with limited resources. Best Practice \& Research Clinical Obstetric and Gynaecology, 2019; https//doi.org/10.1016/j.bpobgyn.2019.03.009. Accessed 26 April 2021.

12. Sotunsa JO, Adeniyi AA, Imaralu JO, Fawole B, Adegbola O, Aimakhu CO, Adeyimi AS, Hunyinbo K, Dada OA, Adetoro OO, Oladapo OT. Maternity near-miss and death among women with postpartum 
haemorrhage: a secondary analysis of the Nigeria Near-miss and Maternal Death Survey. 2019; British Journal of Obstetrics and Gynaecology. 126 (S3):19-25.

13. Association for Improvements in the Maternity Services. Postpartum Haemorrhage. 2017; https//www.aims.org.uk>information>item>pph Accessed 10 May 2021

14. Qayum M., Ali W. \& Waheed N. (2018) Post partum haemorrhage prevention with tranexic acid is effective and safe in comparison to placebo. Parkistan Armed Forces Medical Journal 68(4), 908913.

15. Henriquez DCA, Bloemenkamp KWM, Loeff RM, Zwart JJ, van Roosmalen JJM, Zwaginga JJ, van der Bom JG. Fluid resuscitation during persistent postpartum heamorrhage and maternal outcome: A nationwide cohort study. European Journal of Obstetric \& Gynaecology and Reproductive Biology. 2019; (235): 49-56.

16. Jangsten E. \& Berg M. (2010) Management of the third stage of labour - focus group discussions with Swedish midwives. Midwifery 26 (6), 609-614. https://doi.org/10.1016/j.midw.2008.12.004.

17. Sheldon W. S., Durocher J., Winikoff B., Blum J. \& Trussell J. (2013) How effective are the components of active management of the third stage of labour? BMC Pregnancy \& Childbirth 13:46, http://www.biomedcentral.com/1471-2393/13/46.

18. Senturk S., Kagtci M., Balik G., Arslan H. \& Sahin F. K. (2016) The effects of combined use of methyergonovine and oxytocin during caesearean section in the prevention of post-partum haemorrhage. Basic \& Clinical Pharmacology \& Toxicology 118,338-343.

19. Evensen A, Anderson JM, Fontaine P. Postpartum hemorrhage: Prevention and treatment. American Family Physician. 2017; (95): 442-449.

20. Brenner A., Shakur-Still H., Chaudhri R., Fawole B., Arulkumaran S. \& Roberts I. (2018) The impact of early outcome events on the effects of tranexamic acid in post-partum haemorrhage: an exploratory subgroup analysis of the WOMAN trial. BMC Pregnancy and Childbirth 18:215, https://10.1186/s12884-018-1855-5

21. Gaucher L, Occelli P, Deneux-Tharaux C, Colin C, Gaucherand P, Touzet S, Dupont C. Non-clinical interventions to prevent postpartum haemorrhage and improve its management: A systematic review. European Journal of Obstetric \& Gynaecology and Reproductive Biology. 2019; (240): 300309.

22. Okonufua F, Ntoimo L, Ogungbangbe J, Anjorin S, Imongan W, Yaya S. Predictors of women's utilization of primary health care for skilled pregnancy care in rural Nigeria. BMC Pregnancy and Childbirth. 2018; 18:106, doi:10.1186/s12884-018-1730-4

23. Yaya S, Okonufua F, Ntoimo L, Kadio B, Deuboue R, Imongan W, Balami W. Increasing women's access to skilled pregnancy care to reduce maternal and perinatal mortality in rural Edo State, Nigeria: a randomized controlled trial. BMC Global Health Research and Policy. 2018; 3:12. doi:10.1186/s41256-018-0066-y

24. Ope B W. Reducing maternal mortality in Nigeria: addressing maternal health services' perception and experience. Journal of Global Health Reports. 2020;4:e2020028. Doi.10.29392/001c.12733 
25. Adaniki A.I, Orji E., Adaniki P.O. \& Olaniyan O. (2013) Comparative study of rectal misoprostol to oxytocin infusion in preventing post-partum haemorrhage. Nepal Journal of Obstetrics \& Gynaecology 2(16), 34-37.

26. Gul F., Jabeen M. \& Heema (2018) Frequency, causes and outcome of post-partum haemorrhage at Liaqat Memorial hospital, Kohat, Pakistan. Khyber Medical University Journal 10(2), 90-94.

27. Graneheim UH, Lundman B. Qualitative contenet analysis in nursing research: concepts, procedures, and measures to achieve trustworthiness. Nurse Education Today. 2004; 24: 105-112.

28. Krippendorf K. (2013) Content Analysis: An introduction to its methodology, 3rd edn. Sage Publications Ltd, Thousand Oaks.

29. Krippendorf K. (2018) Content Analysis: An introduction to its methodology, 4th edn. Sage Publications Ltd, Thousand Oaks.

30. Lincoln YS, Guba EG. Naturalist Inquiry. Sage Publications, Newbury Park, California. 1985

31. Kalu FA, Bwalya JC. What makes qualitative research a good research? An exploratory analysis of critical elements. International Journal of Social Science Research 2017; doi:10.5296/ijssr.v5i2.10711

32. Agwu Kalu F, Coughlan B, Larkin P. A mixed methods sequential explanatory study of the psychosocial factors that impact on midwives' confidence to provide bereavement support to parents who have experienced a perinatal loss. Midwifery. 2018; 64:69-76

33. Ikeanyi EM, Ibrahim Al. Does antenatal care attendance prevent anaemia in pregnanacy at term? Nigerian Journal of Clinical Practice. 2015; 18(3): 323-327

34. Yesufu ML. The impact of religion on a secular state: the Nigerian experience. Studia Historiae Ecclesiasticae. 2016; doi:10.17159/2412-4265/2016/255

35. Kalu FA. Women's experiences of utilizing religious and spiritual beliefs as coping resources after miscarriage. Religions. 2019; 10(3), 185; https://doi.org/10.3390/rel10030185. Accessed on 8 June 2021.

36. Thackrah RD, Wood J, Thompson SC. Cultural respect in midwifery service provision for Aboriginal women: longitudinal follow-up reveals the enduring legacy of targeted program initiatives. International Journal of Equity in Health. 2020; 19, 210 https://doi.org/10.1186/s129-020-01325-x. Accessed on 8 June 2021.

37. Lehane D, Campion P. Interpreters: Why should the NHS provide them? British Journal of General Practice. 2018; 68 677): 564-565. https://doi.org/10.3399/bjgp18x699905. Accessed on 8 June 2021.

38. Rogerson SJ. Management of malaria in pregnancy. Indian Journal of Medical Research. 2017; 146(3): 328-333.

39. Al Khaja KAJ, Sequeira RP. Drug treatment and prevention of malaria in pregnancy: a critical review of the guidelines. Malaria Journal 2021; 20, 62. https://s12936-020-03565-2. Accessed on 8 June 2021. 
40. Kolb DA. Experiential Learning: Experience as the source of learning and development. Prentice-Hall, Inc., Englewood Cliffs, New Jersey

41. Kolb DA, Yolb AY. The Experiential Educator: Principles and Practices of Experiential learning. EBLS Press. 2017; Kaunakakai, HI USA.

42. Gungorduk K, Olgac Y, Gulseren V. and Kocaer M. Active management of the third stage of labour: A brief overview of key isues. Turkisk Journal of Obstetrics and Gynaecology. 2018; 15(3): 188-192.

43. Lambert P, Mclntosh MP, Widmer M, Evans L, Rausher M, Kuwana R, Theunissen F, Yeager B, Petach H. Oxytocin quality: evidence to support updated global recommendations on oxytocin for postpartum haemorrage. Journal of Pharmaceutical Policy and Practice 2020; 13, 14. https://doi.org/10.1186/s40545-020-00205-7. Accessed on 16 June 2021.

44. Ostacoli L, Cosma S, Bevilacqua F, Berchialla P, Bovetti M, Carosso AR, Malandrone F, Carletto S, Benedetto C. Psychosocial factors associated with postpartum psycholpogical distress during the Covid-19 pandemic: a cross-sectional study. BMC Pregnancy and Childbirth. 2020; 20, 703. https://doi.org/10.1186/s12884-020-033995. Accessed on 8 June 2021.

45. Gomez-Salgado J, Navarro-Abal Y, Lopez-Lopez MJ, Romero M, Climent-Rodriguez JA. Engagement, passion and meaning of work as modulating variables in Nursing: A theoretical analysis. International Journal of Environmental Research and Public Health. 2019; 16(1): 108 doi: 10.3390/ijerph16010108

46. Mlambo M, Silen C, McGrath C. Lifelong learning, and nurses' continuing professional development, a metasynthesis of the literature. BMC Nursing. 2021; 20, 62. https://doi.org/10.1186/s12912-02100579-2. Accessed on 8 June 2021.

\section{Supplementary Files}

This is a list of supplementary files associated with this preprint. Click to download.

- InterviewguideforPPHinterview.doc 